\title{
Extraction and Purification of Mycobacterial Mycolic Acids
}

Christian M. Dupont and Laurent Kremer*

Laboratoire de Dynamique des Interactions Membranaires Normales et Pathologiques, Université Montpellier, Montpellier, France

*For correspondence: Iremer@univ-montp2.fr

[Abstract] Mycolic acids are major long-chain fatty acids, containing up to 80-90 carbon atoms that represent essential components of the mycobacterial cell wall (Pawelczyk and Kremer, 2014). Each mycobacterial species possesses a specific mycolic acid profile characterized by various chemical modifications that decorate the lipid. Mycolic acids play a critical role in the architecture and impermeability of the cell envelope, hence the natural resistance of mycobacteria to most antibiotic treatments. They are also key determinants of virulence in pathogenic species, including Mycobacterium tuberculosis (M. tuberculosis), the causative agent of tuberculosis. In addition, they are known as the primary target of several first-line and secondline antitubercular drugs. Thus, the unique enzymes involved in the mycolic acid biosynthetic pathway represent an attractive reservoir of targets for future chemotherapy whose developments are particularly warranted in the context of multi-drug-resistant and extensively-drug-resistant strains of $M$. tuberculosis. Herein, we describe a protocol to extract the mycolic acids from mycobacteria. Purification of the various subspecies may be particularly useful for subsequent structural studies involving mass spectrometry or NMR. The qualitative and quantitative biochemical characterization of the mycolic acid pattern by thin layer chromatography can be used to address how drugs alter mycolic acid biosynthesis (Alahari et al., 2007, Hartkoorn et al., 2012), to study the phenotypes of genetically modified mutants affected in this metabolic pathway (Bhatt et al., 2007) or to unravel new mycolic acid regulatory mechanisms (Vilcheze et al., 2014). The same protocol can be applied to all mycobacteria, including environmental and pathogenic species.

\section{Materials and Reagents}

1. Mycobacterial cultures including Mycobacterium tuberculosis, BCG, M. smegmatis and M. abscessus but can be extended to any other species.

2. Tyloxapol $\left(\mathrm{C}_{17} \mathrm{H}_{30} \mathrm{O}_{4}\right)$ (Sigma-Aldrich, catalog number: T8761)

3. Glycerol $\left(\mathrm{C}_{3} \mathrm{H}_{8} \mathrm{O}_{3}, 99.5 \%\right)$ (Euromedex, catalog number: 50405$)$

4. Potassium diphosphate $\left(\mathrm{K}_{2} \mathrm{HPO}_{4}\right)$ (Merck KGaA, catalog number: 1.05104)

5. L-asparagine monohydrate $\left(\mathrm{C}_{4} \mathrm{H}_{10} \mathrm{~N}_{2} \mathrm{O}_{4}, \geq 99 \%\right)$ (Sigma-Aldrich, catalog number: A8381) 
6. Citric acid $\left(\mathrm{C}_{6} \mathrm{H}_{8} \mathrm{O}_{7}, 99 \%\right)$ (Sigma-Aldrich, catalog number: C0759)

7. Ferric ammonium citrate $\left(\mathrm{C}_{7} \mathrm{H}_{13} \mathrm{FeNO}_{7}\right)$ (Sigma-Aldrich, catalog number: F5879)

8. Zinc sulfate heptahydrate $\left(\mathrm{ZnSO}_{4} \cdot 7 \mathrm{H}_{2} \mathrm{O}, \geq 99 \%\right)$ (Sigma-Aldrich, catalog number: $\mathrm{Z4750}$ )

9. Magnesium sulfate $\left(\mathrm{MgSO}_{4}\right)$ (Sigma-Aldrich, catalog number: M7506)

10. Tetrabutyl ammonium hydroxyde (TBAH) $\left(\mathrm{C}_{16} \mathrm{H}_{37} \mathrm{NO}, 40 \%\right.$ solution) (Sigma-Aldrich, catalog number: 178780)

11. Dichloromethane $\left(\mathrm{CH}_{2} \mathrm{Cl}_{2}, \geq 99.8 \%\right)$ (Carlo Erba, catalog number: 412622000)

12. Iodomethane ( $\left.\mathrm{CH}_{3} \mathrm{l}, 99 \%\right)$ (Sigma-Aldrich, catalog number: 1850-7)

13. Diethylether $\left(\mathrm{CH}_{3} \mathrm{CH}_{2} \mathrm{OCH}_{2} \mathrm{CH}_{3}, 99.5 \%\right)$ (Carlo Erba, catalog number: 447521)

14. Hexane $\left[\mathrm{CH}_{3}\left(\mathrm{CH}_{2}\right)_{4} \mathrm{CH}_{3}\right.$, pure isomeric mixture] (Carlo Erba, catalog number: 339852)

15. Ethyl acetate $\left(\mathrm{CH}_{3} \mathrm{COOC}_{2} \mathrm{H}_{5}, 99.9 \%\right)$ (Carlo Erba, catalog number:448251)

16. Molybdophosphoric acid hydrate $\left(\mathrm{H}_{5} \mathrm{Mo}_{12} \mathrm{O}_{41} \mathrm{P}\right)$ (Sigma-Aldrich, catalog number P7390)

17. Rhodamine $6 \mathrm{G}\left(\mathrm{C}_{28} \mathrm{H}_{31} \mathrm{ClN}_{2} \mathrm{O}_{3}\right.$, Dye content $\left.\sim 95 \%\right)$ (Sigma-Aldrich, catalog numberR4127)

18. Middlebrook $7 \mathrm{H} 9$ broth (Difco, catalog number: 271310)

19. Sauton's media (see Recipes)

\section{Equipment}

1. Aluminium Silica gel TLC plates $60 \mathrm{~F}_{254}$ (Merck KGaA, catalog number: 1.05554 .0001 )

2. Plastic Silica gel TLC plates $60 \mathrm{~F}_{254}$ (Merck KGaA, catalog number: 1.05735 .0001 )

3. Round-bottom borosilicate glass tubes (Corning, catalog number: 99449-16) with phenolic screw caps (Corning, catalog number: 9998-15)

4. $10 \mu \mathrm{l}$ capillary tubes Ringcaps (Dutscher Scientific, catalog number: 090512)

5. Spectrophotometer

6. $75 \mathrm{~cm}^{2}$ tissue culture flasks (Sarstedt, catalog number: 83.1813 )

7. $37^{\circ} \mathrm{C}$ incubator or $30^{\circ} \mathrm{C}$ incubator for growing mycobacteria such as $\mathrm{M}$. marinum Notes: Atypical mycobacteria and BCG should be handled according to institutional standards of practice for biosafety whereas M. tuberculosis cultures should be handled in biosafety level 3 facility.

8. $50 \mathrm{ml}$ conical Corning CentriStart tubes (Corning, catalog number: 430828)

9. $15 \mathrm{ml}$ conical Corning CentriStart tubes (Corning, catalog number: 430790)

10. Centrifuge with swinging bucket rotor for spinning down bacterial cultures (for example, Prolabo, model: HR340 with the $15 \mathrm{ml}$ and $50 \mathrm{ml}$ adaptors)

11. $\mathrm{pH}$ meter

12. Ultrasonic waterbath (Bandelin Sonorex, model: RK102H)

13. Stuart Rotator SB3 
14. Stuart block heater (Stuart, model: SBH200D)

15. TLC developing tank

16. Zymark TurboVap evaporator (Biotage, catalog number: C133718)

17. Handheld UV lamp VL-6-LC $365 \mathrm{~nm} / 254 \mathrm{~nm}$

18. 1800W Heat gun (Power Performance, model: PHG1800T2)

19. Reagent Sprayer, all glass, with $100 \mathrm{ml}$ Erlenmeyer flask (CAMAG, catalog number: 022.6100)

20. TLC Spray Cabinet (CAMAG, catalog number: 022.6230)

\section{Procedure}

A. Inoculation and growth of mycobacterial cultures

1. Inoculate liquid cultures (in either Sauton's broth or Middlebrook $7 \mathrm{H} 9$ broth) of mycobacteria from frozen stocks, prepared from mid-log phase mycobacterial cultures $\left(\mathrm{OD}_{600}=0.8\right.$ to 1.0$)$ that were frozen in $50 \%$ glycerol at $-80{ }^{\circ} \mathrm{C}$. For inoculation, the doubling rate of the mycobacterial species needs to be kept in mind. M. smegmatis doubles approximately every 3-4 h, whereas BCG and $M$. tuberculosis double approximately every $24 \mathrm{~h}$ at $37^{\circ} \mathrm{C}$.

2. These pre-cultures are inoculated in $25 \mathrm{ml}$ Sauton's broth medium (or Middlebrook $7 \mathrm{H} 9$ broth) in $75 \mathrm{~cm}^{2}$ tissue culture flasks. Include appropriate antibiotics if required for maintaining a plasmid when growing a transformed mycobacterial strain.

3. The mycobacterial cultures are incubated at $37^{\circ} \mathrm{C}$ with no or slow shaking. Measure the $\mathrm{OD}_{600}$ of the culture and harvest exponentially growing mycobacteria $\left(\mathrm{OD}_{600}=0.8\right.$ to 1.0 ) by centrifugation at 3,000 rpm for $10 \mathrm{~min}$ at room temperature. Discard the supernatant.

4. Resuspend the pellet in $5 \mathrm{ml}$ of water and transfer the bacterial suspension in $15 \mathrm{ml}$ conical plastic tubes. Pellet the bacterial cells again by centrifugation. This wash step is important to remove the remaining traces of medium. The bacterial pellet is then transferred to a round-bottom glass tube prior to lipid hydrolysis. All subsequent procedures will be performed in glass tubes due to the presence of organic solvents.

B. Fatty acid/mycolic acid extraction

1. Resuspend the bacterial pellet in $2 \mathrm{ml}$ of tetrabutyl ammonium hydroxyde (TBAH) and incubate overnight at $100^{\circ} \mathrm{C}$ using a heating block. This step allows complete fatty/mycolic acid hydrolysis.

2. The next day, let the tube cool down at room temperature and proceed with methyl esterification of the fatty/mycolic acids: To the $2 \mathrm{ml}$ of TBAH mixture, add $4 \mathrm{ml} \mathrm{CH}_{2} \mathrm{Cl}_{2}$, $300 \mu \mathrm{CH}_{3} \mathrm{l}$ and $2 \mathrm{ml}$ water. Mix the tube for $1 \mathrm{~h}$ at room temperature on a rotator. 
3. Centrifuge at $3,500 \mathrm{rpm}$ for $10 \mathrm{~min}$ at room temperature. This will allow to separating the mixture in two phases: A lower organic phase containing the lipids and an upper aqueous phase. Discard the upper phase to waste.

4. Add $4 \mathrm{ml}$ of water, mix the tube for $\mathbf{1 5} \mathrm{min}$ and spin down at 3,500 rpm for $10 \mathrm{~min}$ at room temperature. Repeat this wash step 2 more times and remove the upper phase to waste.

5. Dry the lower organic phase in the same tube under a stream of nitrogen using a TurboVap evaporator. Evaporation of the organic phase takes around $30 \mathrm{~min}$.

6. To the dried residue, add $3 \mathrm{ml}$ diethylether and sonicate in a waterbath for $10 \mathrm{~min}$ at room temperature.

7. Centrifuge at $3,500 \mathrm{rpm}$ for $10 \mathrm{~min}$ at room temperature and, using a Pasteur pipette, transfer the fatty acid/mycolic acid methyl esters in a new glass tube.

8. Evaporate the diethylether under a stream of nitrogen and resuspend the residue in 100$200 \mu \mathrm{CH}_{2} \mathrm{Cl}_{2}$.

C. Thin layer chromatography

1. Load 10-30 $\mu \mathrm{l}$ on an aluminium TLC plate using $10 \mu \mathrm{l}$ capillary tubes (Figure 1 ).

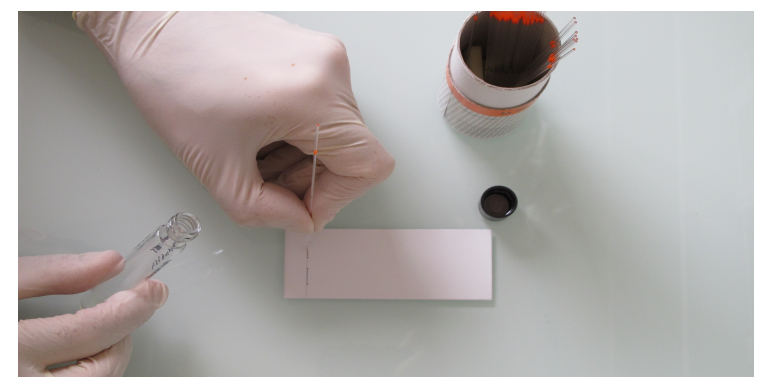

Figure 1. Loading the lipid samples with a capillary tube directly at the origin of the TLC plate

2. Fatty acid methyl esters (FAMES) and mycolic acid methyl esters (MAMES) are separated by thin layer chromatography in a TLC tank using hexane/ethyl acetate (19:1, $\mathrm{v} / \mathrm{v})$. When the solvent front reaches the top of the TLC plate, the plate is taken out, dried very briefly and placed again in the tank for a second round of migration. This allows to better separate the various mycolic acid subspecies.

3. Spray the TLC plate with $5 \%$ ethanolic molybdophosphoric acid using a reagent sprayer in a TLC spray cabinet (Figure 2).

4. Lipids are revealed following charring using a heat gun, which emits a stream of very hot air. Bands corresponding to the different mycolic acids will appear as represented in Figure 3. 


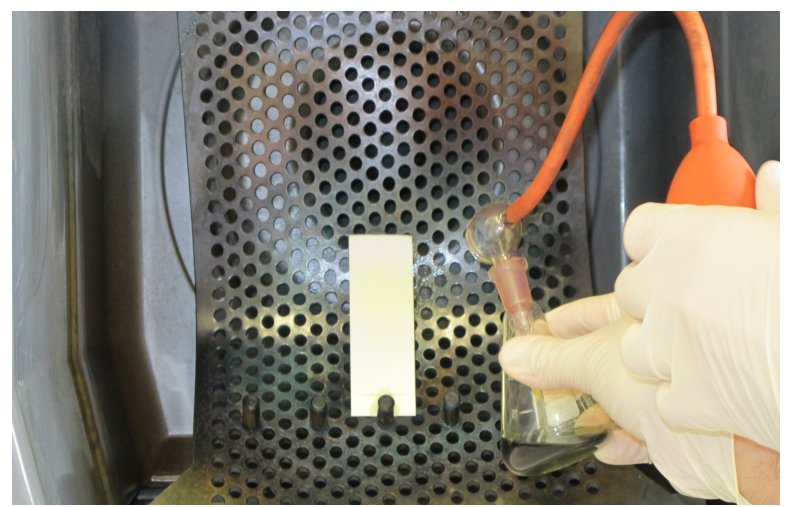

Figure 2. Homogenous spraying of the TLC plate with molybdophosphoric acid in a spray cabinet

D. Purification of the mycolic acid subspecies

1. Mycolic acid methyl esters are loaded on preparative plastic TLC plates and separated, as described above.

2. Spray the plate with $0.01 \%$ ethanolic Rhodamine $6 \mathrm{G}$ and visualize the mycolic acid subspecies using a handheld UV lamp.

3. Scrape off the bands corresponding to the individual mycolic acid subspecies and put the lipid-loaded silica powder into a glass tube.

4. Extract from mycolic acid with diethyl ether as mentioned above (steps B6-8).

5. If necessary, resolve again the lipids individually on new preparative TLC plates and repeat the whole procedure.

6. Evaporate the diethylether under a stream of nitrogen and resuspend the lipids in 100$200 \mu \mathrm{CH}_{2} \mathrm{Cl}_{2}$.

7. Assess purity of the mycolic acid methyl esters on a standard TLC plate as described in steps C1-4. 


\section{Representative data}

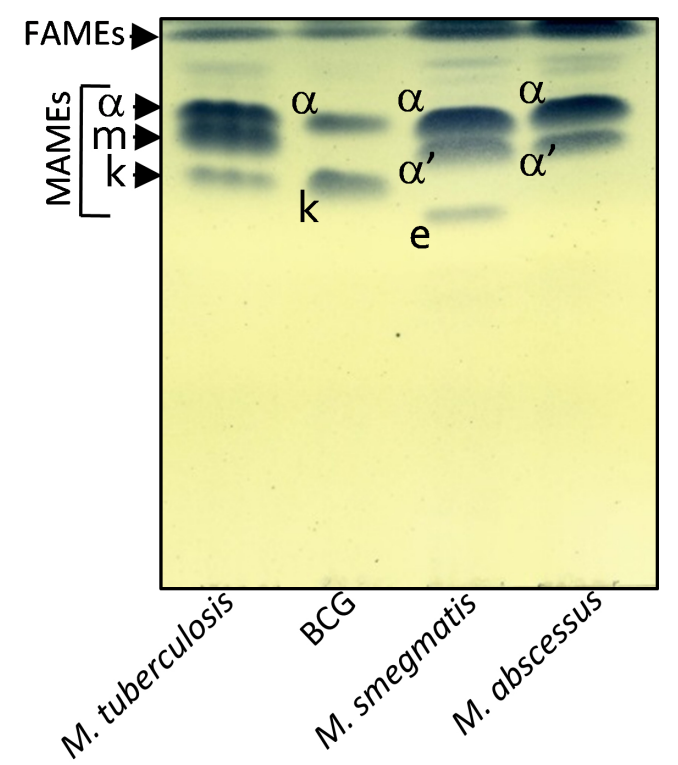

Figure 3. Mycolic acid profile of various mycobacterial species. Cultures of $M$. tuberculosis CDC1551, BCG Pasteur, M. smegmatis mc $^{2} 155$ and $M$. abscessus CIP104536 ${ }^{\top}$ were grown in Sauton's medium. FAMEs and MAMEs were extracted and analyzed by one-dimensional TLC using hexane/ethyl acetate $(19: 1, v / v ; 2$ runs) and revealed by spraying the plate with molybdophosphoric acid followed by charring. -, m, k, corresponding respectively to alpha-, methoxy- and keto-mycolic acids are characteristic of $M$. tuberculosis. BCG Pasteur lacks methoxy mycolic acids. M. abscessus possesses only $\square$ and '-mycolic acids shared with $M$. smegmatis which produces also epoxy-myolic acids (e). FAME, fatty acid methyl ester; MAME, mycolic acid methyl ester.

\section{$\underline{\text { Notes }}$}

For all steps involving organic solvents, use glass pipettes and tubes and work under a chemical hood.

\section{$\underline{\text { Recipes }}$}

1. Sauton's media ( $1 \mathrm{~L})$

Dipotassium phosphate $0.5 \mathrm{~g}$

L-asparagine monohydrate $4.0 \mathrm{~g}$

Citric acid monohydrate $2.0 \mathrm{~g}$

Ferric ammonium citrate $0.05 \mathrm{~g}$ 
$1 \%$ zinc sulfate monohydrate $0.1 \mathrm{ml}$

Magnesium sulfate heptahydrate $0.5 \mathrm{~g}$

$100 \%$ glycerol $60 \mathrm{ml}$

$5 \%$ tyloxapol $5 \mathrm{ml}$

Water to $1 \mathrm{~L}$

Dissolve the above components

Adjust $\mathrm{pH}$ to 7-7.2 with $5 \mathrm{~N} \mathrm{NaOH}$

Make up the volume to $1 \mathrm{~L}$ with water

Autoclave for $10 \mathrm{~min}$

Store at room temperature

\section{Acknowledgments}

The authors wish to thank Vaincre la Mucoviscidose for funding CMD. This protocol was adapted from a previous work by this protocol was adapted from a previous work by Besra (1998).

\section{$\underline{\text { References }}$}

1. Alahari, A., Trivelli, X., Guérardel, Y., Dover, L. G., Besra, G. S., Sacchettini, J. C., Reynolds, R. C., Coxon, G. D. and Kremer, L. (2007). Thiacetazone, an antitubercular drug that inhibits cyclopropanation of cell wall mycolic acids in mycobacteria. PLoS One 2(12): e1343.

2. Besra, G. S. (1998). Preparation of cell-wall fractions from mycobacteria. Methods Mol Biol 101: 91-107.

3. Bhatt, A., Fujiwara, N., Bhatt, K., Gurcha, S. S., Kremer, L., Chen, B., Chan, J., Porcelli, S. A., Kobayashi, K., Besra, G. S. and Jacobs, W. R., Jr. (2007). Deletion of kasB in Mycobacterium tuberculosis causes loss of acid-fastness and subclinical latent tuberculosis in immunocompetent mice. Proc Natl Acad Sci U S A 104(12): 5157-5162.

4. Hartkoorn, R. C., Sala, C., Neres, J., Pojer, F., Magnet, S., Mukherjee, R., Uplekar, S., Boy-Rottger, S., Altmann, K. H. and Cole, S. T. (2012). Towards a new tuberculosis drug: pyridomycin - nature's isoniazid. EMBO Mol Med 4 (10): 1032-1042. 